\title{
Analysis on Moisture Migration Law in Loess Fill Subgrade
}

www.jestr.org

\author{
Dong Dingming ${ }^{1}$, Gao Haijun ${ }^{1, *}$, Zhao Qi ${ }^{1}$, Dong $\mathbf{Q i}^{2}$ and Zhou Jieli ${ }^{3}$ \\ ${ }^{I}$ Yan'an Highway Administration Bureau of Shaanxi Province, Yan'an City, Shaanxi Province, 716100, China \\ ${ }^{2}$ Shaanxi Science and Technology Holding Group Co., Ltd., Xi'an City, Shaanxi Province, 710077, China \\ ${ }^{3}$ Carnegie Mellon University, 5000 Forbes Ave, Pittsburgh, PA 15213, United States
}

Received 9 May 2019; Accepted 30 July 2019

\begin{abstract}
With the development of the highway construction industry in loess areas, exploring the causes of damage in loess fill subgrade has become an important topic that people have been widely concerned about. Specifically, the law of moisture migration inside the loess fill subgrade is the key to solve various loess road damage due to its special water sensitivity. Existing research has mainly focused on the influence of temperature potential and other factors on moisture migration in subgrade. However, the influence of the nature of the loess fill subgrade on the moisture migration law still lacks systematic research. In this study, a series of experiments on moisture migration in loess fill subgrade under different degrees of compaction were performed using a self-made moisture migration test device, which revealed moisture migration law in the fill subgrade. Experimental results show that water migration rate is negatively correlated with a number of wetting-drying cycle, degree of compaction, and initial water content. The final volume moisture content decreases with the increase of migration height after moisture migration is stabilized. Spaces among soil particles are small, and the soil particles are close when the degree of compaction is high. Accordingly, energy consumption for moisture migration is high, and the moisture migration decelerates. Under the same dry density condition, as the initial water content increases, the time to reach the equilibrium of water migration is shorter, and the migration rate is faster. This result also reveals that the key for controlling subgrade quality is to strictly control the degree of compaction, waterproof property, and drainage. This study can provide theoretical references to prevent damage in loess fill subgrade and waterproof the design and construction of subgrade.
\end{abstract}

Keywords: Loess fill subgrade, Dry density, Initial water content, Humidification-dehumidification, High fill area, Moisture migration

\section{Introduction}

Loess is found extensively in China, mainly in the northern and northwestern parts of the country, and the northwest is the largest area in the Loess Plateau and worldwide. With the large-scale efforts of Western China Development and the implementation of "The Belt and Road" strategy, increasing number of highways has been constructed in loess areas to narrow the gap between the eastern and western portions of the country and drive collective prosperity. Limited by special terrains and influence from the construction economy in loess areas, the loess fill subgrade with loess as the main fill subgrade is inevitable. Different from other packings used for subgrade construction, loess is a type of special quaternary deposit. Loess is mainly characterized by macropore, collapsibility, structure, and softening upon wetting. Meanwhile, loess-induced damage has spread everywhere in loess regions due to the unique external structure and internal characteristics of loess.

The loess subgrade is a structure formed by the layered backfilling of remolding soils that are then compacted using strong dynamic compaction and a rolling machine. Influenced by properties of packing, the subgrade has certain collapsibility and incomplete consolidation. A subgrade may

*E-mail address: 1739520669@qq.com

ISSN: $1791-2377$ C 2019 School of Science, IHU. All rights reserved.

doi:10.25103/iestr.124.15 develop deformation settlement in the operation stage due to the long-term influence of gravity and vehicular loads. It may also develop significant uneven settlements and even transverse and longitudinal cracks due to serious vehicular overloads. Surface water formed by rainfall or melted snow increases water content of the packing as it migrates into the fill subgrade along cracks. Moreover, moisture migrates from regions of high water content to regions of low water content. Water content in packing changes with temperature, which results in humidification and dehumidification processes in the subgrade. Water migration under humidification and dehumidification conditions decreases soil strength, which results in further development of cracks. The mechanical properties of the filler are affected by humidification, dehumidification and moisture migration, which cause a series of damage problems such as pavement cracking, differential settlement of subgrade, engineering quality attenuation and subgrade instability, thus accelerating the damage of highway structures and shortening the service life of highways, and cause unnecessary losses.

At present, moisture migration in soil mass has attracted wide engineering attention. Numerous studies on engineering properties of loess under wetting-drying cycle have been conducted [1-3]. However, only few studies have discussed the influence of humidification-dehumidification cycle of soil packing and compacted as highway subgrade on engineering construction. Currently, most related studies have focused on the moisture migration law of loess [4-5], 
whereas few studies are available on moisture migration law under humidification-dehumidification cycle and effect of moisture migration on subgrade engineering. Moisture migration law in loess fill subgrade under humidificationdehumidification cycle is the key to success to similar projects. Thus, the study of moisture migration law in loess fill subgrade is necessary. Moisture migration law in loess fill subgrade has to be disclosed to guide engineering practices.

In this study, a series of moisture migration tests in packing soil samples in a highway subgrade in the northern Shaanxi Province are performed using a self-made experimental apparatus. Key attention is paid to the influencing factors of humidification-dehumidification cycle, dry density, and initial water content. Influencing laws of the properties of loess fill subgrade on moisture migration are disclosed.

\section{State of the art}

Existing studies on moisture migration in subgrade have mainly focused on the influence of the surrounding climate on moisture migration. Thomas et al. [6-7] used the measured evaporation data and fluid-structure interaction theory of unsaturated soil in analyzing the seasonal variation of clay water content. Wang [8] constructed a hydrothermal coupling model for permafrost subgrade considering the effect of temperature and revealed the transverse differences of temperature field and moisture content in the permafrost subgrade. Fourie et al. [9] discussed the relationship of the depth of rainfall penetration with the moisture content of slope, matric suction, rainfall intensity, and duration of rainfall on the basis of a fly ash slope in an area in South Africa; the penetration rate of rainfall was part of the preliminary study. Simmori et al. [10] simulated transient seepage on the basis of Galerkin finite element method and studied the transient seepage and stability of an artificial slope in Hong Kong under different rainfall intensities, initial surface conditions, and boundary conditions. They also studied the parameters related to slope stability. Through a field investigation, Zhang et al. [11] discovered that asphalt pavement altered the exchange interface between the atmosphere and soil water and intensified water accumulation in the subgrade. Wang et al. [12] simulated a sunny-rainy climate alternation and continuous rainfall conditions using a self-made experimental apparatus and disclosed the moisture migration law in the subgrade under these conditions. Bai et al. [13] replicated a full coupling numerical simulation of a frozen soil temperature field and water field by solving the hydrothermal coupling equation of frozen soils. Gasmo et al. [14] performed a numerical analysis on the relationship among rainfall intensity, osmotic coefficient, matric suction, and pore water pressure in an unsaturated soil slope. On this basis, variations of the safety coefficient have been studied. McRoberts and Morgenstern [15] proposed an effective stress and melting-solidification theory. They believed that the excess pore water pressure increased the easy gliding surface, which caused instability of slope during the thawing-solidification of frozen soil on the slope. Lam et al. [16] constructed a finite element governing equation on moisture migration in saturatedunsaturated soil mass, which had been widely applied in solving moisture migration problems under isothermal conditions. Cui [17] monitored the responses of the subgrade of the Rouen test highway in France to environmental changes, including suction, temperature, and water content. Cao [18] monitored the water content at different positions and depths of a real project and found small moisture migration in fillers due to potential temperature in winter. $\mathrm{Li}$ et al. [19] established a coupling model of thermal and seepage fields on the basis of governing equations on moisture migration and heat transmission. They found that atmospheric environmental changes could significantly influence the water content of a subgrade; this effect was extremely evident in a shallow subgrade. Xie [20] and Liu [21] reported the water seepage laws and saturation depth in loess fill subgrade under different rainfall intensities by combining simulation test and numerical simulation. Liu [22] studied moisture migration law in a subgrade under the influences of capillary water, rainfall seepage, and hydrothermal coupling effect. Certain scholars have also attained results on moisture migration law in fill subgrade from the perspectives of freezing-thawing cycle and moisture migration [23-27]. However, few studies have been concerned with the influence of the physical properties of loess fill subgrade on moisture migration law.

The remainder of this study is organized as follows. Section 3 illustrates the experimental design. Section 4 analyzes the experimental results. Finally, Section 5 summarizes the conclusion.

\section{Methodology}

\subsection{Preparation of soil samples}

Loess samples were collected from a loess fill subgrade of a highway in the northern Shaanxi Province. The loess samples were yellowish-brown, slightly wet, and uniform in texture. They were sealed and carried back to the laboratory to prevent water evaporation. The specific indicators of soil samples are shown in Table. 1.

Table 1. Statistics on the physical properties of loess samples

\begin{tabular}{cccccc}
\hline $\begin{array}{c}\text { Water } \\
\text { content } \\
(\%)\end{array}$ & $\begin{array}{c}\text { Optimal } \\
\text { water } \\
\text { content } \\
\mathbf{( \% )}\end{array}$ & $\begin{array}{c}\text { Plastic } \\
\text { limit } \\
\mathbf{( \% )}\end{array}$ & $\begin{array}{c}\text { Liqui } \\
\text { d limit } \\
\mathbf{( \% )}\end{array}$ & $\begin{array}{c}\text { Plasticity } \\
\text { index }\end{array}$ & $\begin{array}{c}\text { Relative } \\
\text { density } \\
\text { of soil } \\
\text { particle } \\
\text { s }\end{array}$ \\
\hline 15.2 & 13.5 & 20.6 & 31.2 & 10.6 & 2.71 \\
\hline
\end{tabular}

\subsection{Experimental apparatus}

Pictures and structures of the self-made moisture migration experimental apparatus are shown in Figs.1 and Figs.2, respectively. This equipment is composed of five parts, namely, constant water level acquisition device, leveling framework, constant water level tube, water migration device, and soil humidity recorder. The constant water level acquisition device is connected to the constant water level tube through water pipes, and the constant water level tube is connected to the moisture migration device through the water pipes. The core of this device is the moisture migration device, which is made of a $200 \mathrm{~mm}$ (diameter) $\times$ $600 \mathrm{~mm}$ (height) organic glass tube. A moisture transducer is inserted into the moisture migration device every $50 \mathrm{~mm}$ to measure the volume moisture content in soil mass. The range, accuracy, and resolution of water transducer are 0.0 $100 \%$, $\pm 3 \%$, and $0.1 \%$, respectively. Moisture data in soil mass are concentrated in the monitoring instrument, which enable the apparatus to realize continuous data acquisition throughout the test. The temperature in the working environment is $-30{ }^{\circ} \mathrm{C}$ to $70{ }^{\circ} \mathrm{C}$, which meets the test 
requirements. Moreover, porous stones are placed at the bottom of the soil container to prevent scoring damage to the soil samples.

constant water level acquisition device

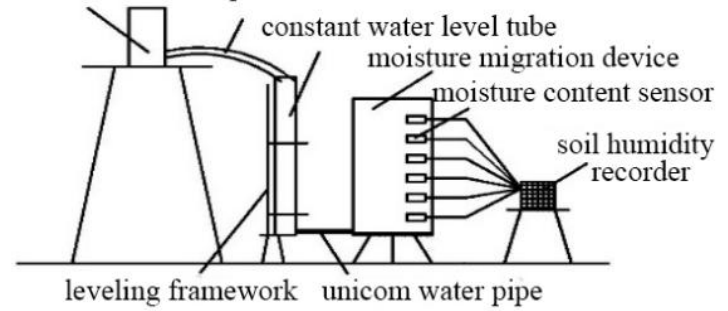

Fig.1. Schematic of moisture migration device

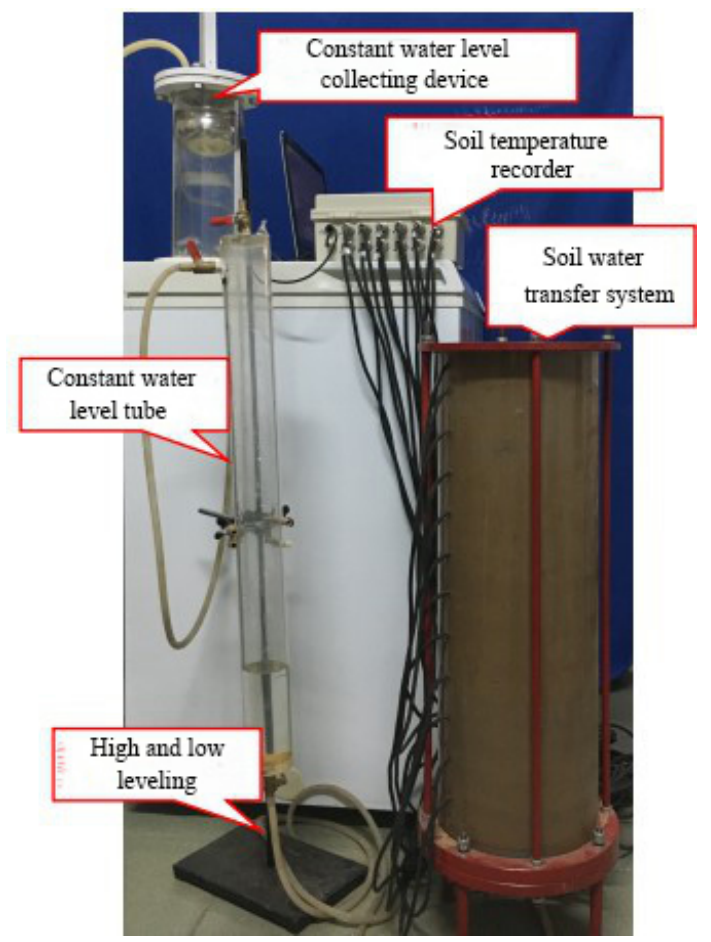

Fig. 2. Physical map of moisture migration device

\subsection{Experiment}

A total of eight groups of samples were collected for moisture migration tests under different humidificationdehumidification cycles, dry densities, and initial water contents. The test conditions of eight groups of soil samples were designed according to Table. 2 to Table. 4.

Table 2. Number of soil samples with different humidification-dehumidification cycles

\begin{tabular}{c|c|c}
\hline Sample number & $\begin{array}{c}\text { Dry density } \\
\left(\mathrm{g} / \mathrm{cm}^{3}\right)\end{array}$ & $\begin{array}{c}\text { Water content } \\
(\%)\end{array}$ \\
\hline 1 & 1.4 & 14.8 \\
2 & 1.4 & 19.8 \\
\hline
\end{tabular}

Table 3. Number of soil samples with different dry densities

\begin{tabular}{c|c|c}
\hline Sample number & $\begin{array}{c}\text { Dry density } \\
\left(\mathrm{g} / \mathrm{cm}^{3}\right)\end{array}$ & $\begin{array}{c}\text { Water content } \\
\mathbf{( \% )}\end{array}$ \\
\hline 3 & 1.3 & 15.0 \\
4 & 1.4 & 14.9 \\
5 & 1.5 & 15.0 \\
\hline
\end{tabular}

Table 4. Number of soil samples with different initial water contents

\begin{tabular}{c|c|c}
\hline Sample number & $\begin{array}{c}\text { Dry density } \\
\left(\mathrm{g} / \mathrm{cm}^{3}\right)\end{array}$ & $\begin{array}{c}\text { Water content } \\
\mathbf{( \% )}\end{array}$ \\
\hline 6 & 1.4 & 10.1 \\
7 & 1.4 & 14.9 \\
8 & 1.4 & 19.8 \\
\hline
\end{tabular}

The designed water content of the soil samples was analyzed through a water membrane migration method. During dehumidification, practical conditions were simulated under natural drying. Water content was measured by a moisture transducer. The experiment was terminated after the stabilization of the wetting peak. The dehumidification-humidification-dehumidification process was a complete humidification-dehumidification cycle.

The degree of compaction was controlled by dry density. Loess samples were placed into a moisture migration device and compacted layer by layer until the desired dry density was reached. Moisture transducers were fixed. Moisture migration tests were initiate dafter samples were prepared and terminated after the stabilization of the wetting peak.

In the experiment, water was supplied by a constant water level acquisition device and a constant water level tube. Moreover, water content data were collected by a moisture transducer as the moisture migration continued and then fed back to the soil humidity recorder. The water level device was kept open to assure that the entire experiment was conducted under an open environment. The relationship curves of the duration of moisture migration and the height of wetting peak under different conditions were drawn on the basis of the experimental results.

\section{Result analysis and discussion}

4.1 Moisture migration laws in soils under humidification-dehumidification cycles

The relationship curve between the advancing distance of the wetting peak and the number of humidificationdehumidification cycle is shown in Fig. 3. Similar laws are observed in three humidification-dehumidification cycles. The advancing distance of the wetting peak increases with time and finally tends to be stable. In addition, a linear positive relationship exists between the advancing distance and the duration of water migration. Finally, the slope of the relationship curve decreases gradually. This relationship curve can be divided into two stages, namely, quick and slow changing stages, with the former lasting for a short period (approximately $5 \mathrm{~h}$ ). In the quick changing stage, the advancing distance of the wetting peak achieves a linear growth with time.

In terms of the advancement distance of the wetting front, the first humidification process $>$ the second humidification process $>$ the third humidification process; in terms of the water migration velocity, the first humidification process $>$ the second humidification process $>$ The third humidification process. The advancing distance of wetting peak decreases, and moisture migration decelerates with the increase in number of humidification processes. From the perspective of energy, each wettingdrying cycle will have to consume a substantial amount of energy to overcome gravity and frictional power. As a result, energy for moisture migration decreases continuously, which results in the decrease of migration height and speed. Water migration is divided into quick and stable migration stages. 


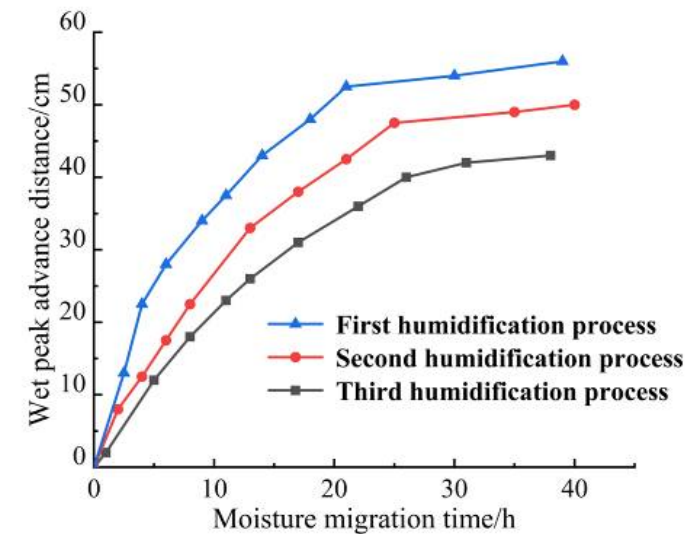

(a)

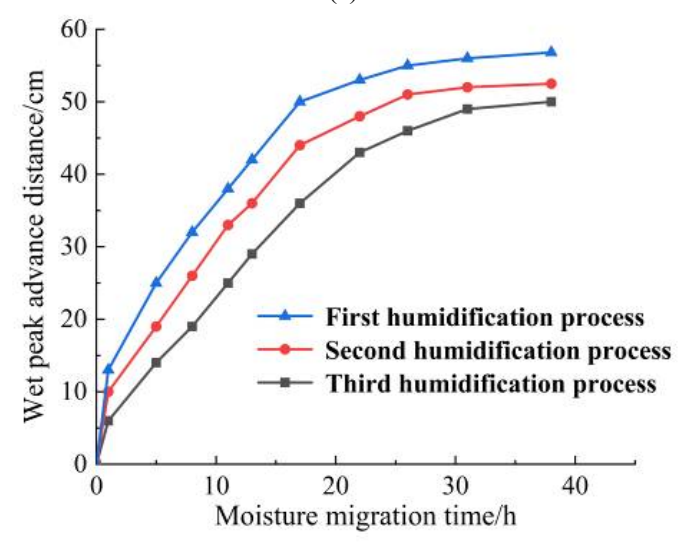

(b)

Fig. 3. Relationship curves between moisture migration and number of humidification-dehumidification cycles. (a) Sample 1. (b) Sample 2

As shown in Fig. 3, the relationship between the time of water migration $(t)$ and the advancing distance of wetting peak $(L)$ can be expressed as follows:

$$
L=\frac{t}{a+b t}
$$

Where $t$ is the time of moisture migration, unit $h$, and $L$ is the advancing distance of the wetting peak, unit $\mathrm{cm}$.

\subsection{Effect of dry density on moisture migration law in soil mass}

The relationship curves between moisture migration law and dry density are shown in Fig. 4. Moisture migration laws in three soil samples are basically consistent. The initial water content is not entirely equal, which is caused by experimental operation and errors of the moisture transducer. However, error accounts for a small percentage and does not affect moisture migration law. As time passes, the wetting peak area of the three soil samples migrates from bottom to top gradually, and the moisture content increases accordingly. On the basis of the analysis of numerical values, reaching the wetting peak with the increase of dry density takes a longer time. By contrast, the moisture migration speed decreases because soil particles are closer when the dry density is higher, which increases resistance against water migration and stronger power for moisture migration. As a result, the moisture migration speed decreases.

Soil particles are simplified into spheres and divided into numerous microelement sections on the basis of the cross section of the samples (Fig. 5). Any one region is selected from the microelement section. The sectional arrangement of soil particles in this region is shown in Fig. 6. The migration path can be viewed as a circular tube.

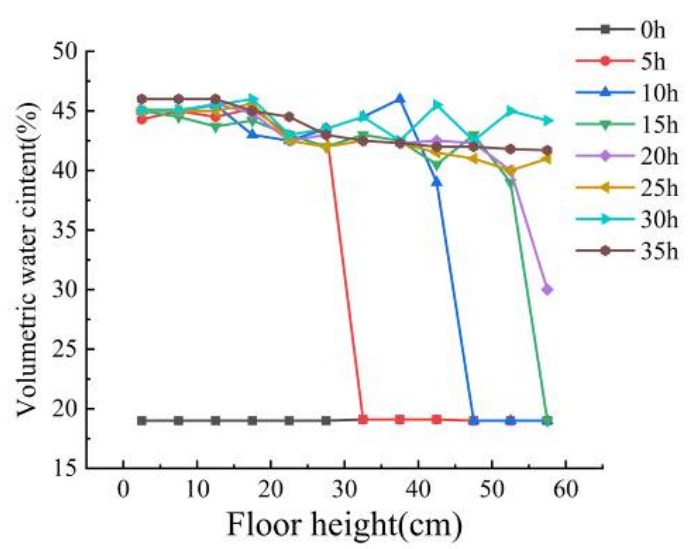

(a)

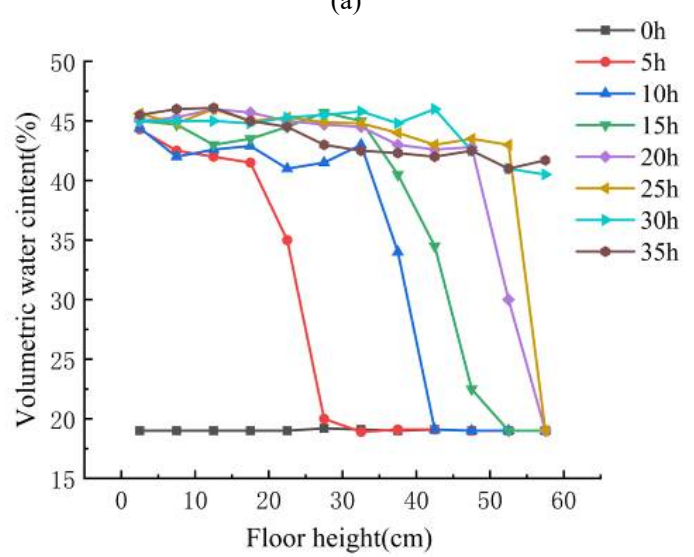

(b)

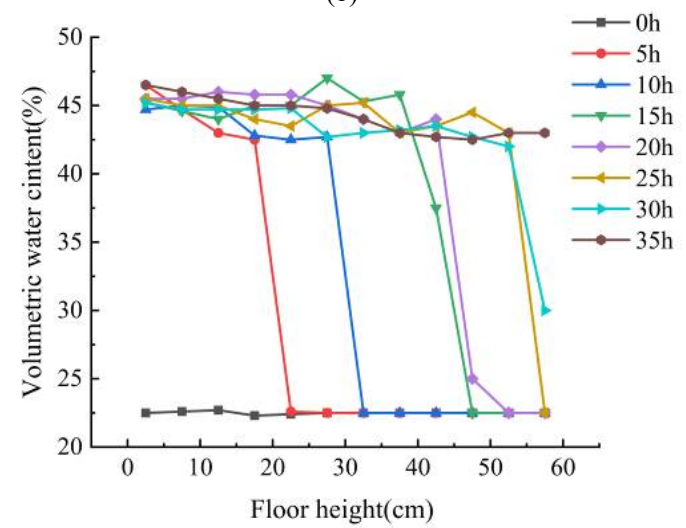

(c)

Fig.4. Relation Relationship curve between moisture migration laws and dry density. (a) Sample 3. (b) Sample 4. (c) Sample 5

Along the height range, the moisture migration process can be approximated as laminar flow. Water is hypothesized to migrate in countless equal-height circular tubes in the samples. Differences in the water head and the temperature are the impetus of moisture migration. Gravity and frictional force of the circular tube are the influencing factors of water migration. The following energy equation is established:

$W=W_{G}+W_{f}+W_{\omega}$

where $W$ is the impetus of moisture migration, which consists of water head difference, temperature difference, and soil-water potential; $W_{G}$ is the power of gravity; $W_{f}$ is 
the power of frictional force; and $W_{\omega}$ is the energy needed to reach the same water content.

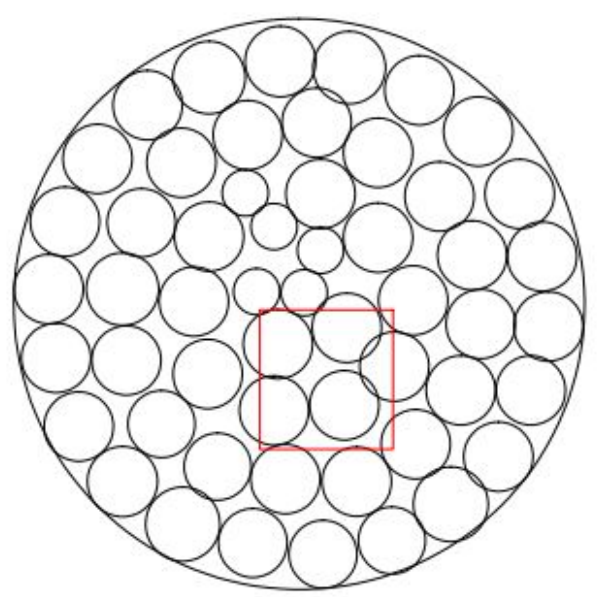

Fig .5. Micro element section

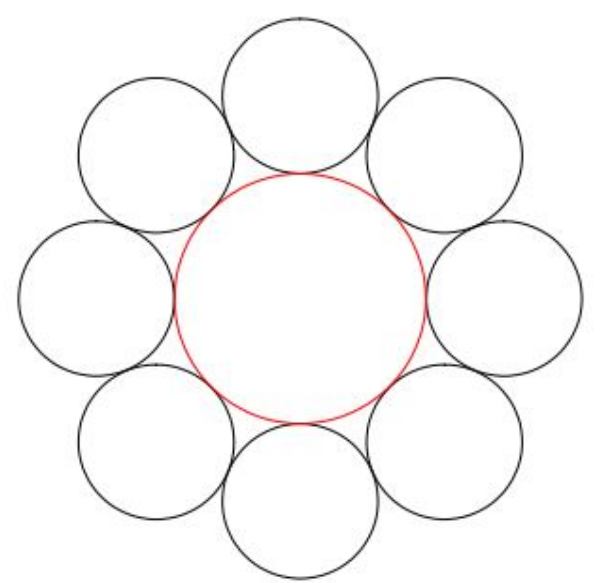

Fig. 6. Section of soil particle arrangement

On the basis of Equation (2), given the same initial water content, the space among particles is narrowed with the increase in dry density. Relatively more circular tubes in the same element are present, which brings higher power of frictional force, higher energy to reach the same water content, higher kinetic energy, and longer time to reach the same advancing distance of the wetting peak. As a result, moisture migration decelerates.

Standard deviations of migration distance of soil samples with different dry densities at different moments of the stable stage are shown in Table 5. The standard deviation of migration distance is basically steady in the stable stage. Water migration in this stage is relatively smooth, and a stable migration path is formed in a short period. Moreover, this stage is a humidification stage under the effect of head pressure known as the hydraulic pressure-induced humidification stage. Water content drops significantly when the wetting peak area of moisture migration reaches a certain height, and the power of the impetus of moisture migration and energy dissipation during moisture migration are basically equal. Subsequently, a capillary effect becomes the impetus for moisture migration. Moisture migration enters into the capillary-controlled stage, in which water migration speed decreases significantly. However, moisture migration becomes stable on a height of wetting peak surface. The general moisture migration process is shown in Fig.7.
Table 5. Standard deviation of soil samples with different dry densities at different moments of stable stage

\begin{tabular}{c|c|c|c}
\hline & $\begin{array}{c}\text { Dry density=1.3 } \\
\mathrm{g} / \mathrm{cm}^{3}\end{array}$ & $\begin{array}{c}\text { Dry density }=1.4 \\
\mathrm{~g} / \mathrm{cm}^{3}\end{array}$ & $\begin{array}{c}\text { Dry density }=1.5 \\
\mathrm{~g} / \mathrm{cm}^{3}\end{array}$ \\
\hline $5 \mathrm{~h}$ & 1.1935 & 0.7465 & 1.4761 \\
$10 \mathrm{~h}$ & 1.0812 & 0.6349 & 1.2787 \\
$15 \mathrm{~h}$ & 1.5279 & 1.1400 & 0.6233 \\
$20 \mathrm{~h}$ & 1.5337 & 1.1770 & 0.8599 \\
$25 \mathrm{~h}$ & 1.7312 & 0.7582 & 0.9368 \\
$30 \mathrm{~h}$ & & 1.1900 & 0.9582 \\
$35 \mathrm{~h}$ & & & 1.1256 \\
\hline
\end{tabular}

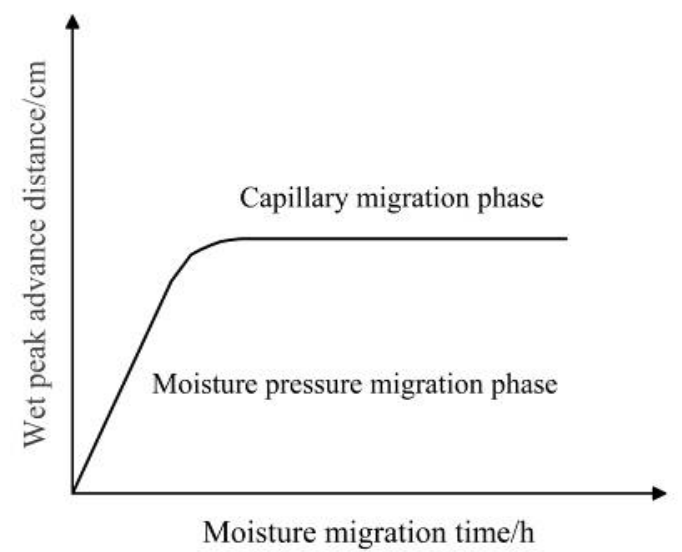

Fig. 7. Stage divisions of moisture migration

4.3 Effect of initial water content on moisture migration Moisture migration laws under different initial water contents but same dry density are shown in Fig. 8. The variation laws of moisture content of three loess samples with height to the bottom plate are consistent throughout the experiment. The three selected loess samples have different initial water contents, which results in different initial volume water contents. However, the moisture distribution in the three samples is relatively uniform. Moisture migrates upward continuously as passes; however, the broken line is still characteristic of bottom sparsity and upper density. Given the same dry density, the overall moisture migration speed is positively related with the initial water content. In sum, porosity among soil particles is approximately equal given the same dry density. Small power is required to reach the equilibrium of moisture migration. In addition, energy is sufficient to overcome the power of gravity when the initial water content is high. Moisture migration is positively correlated with the initial water content.

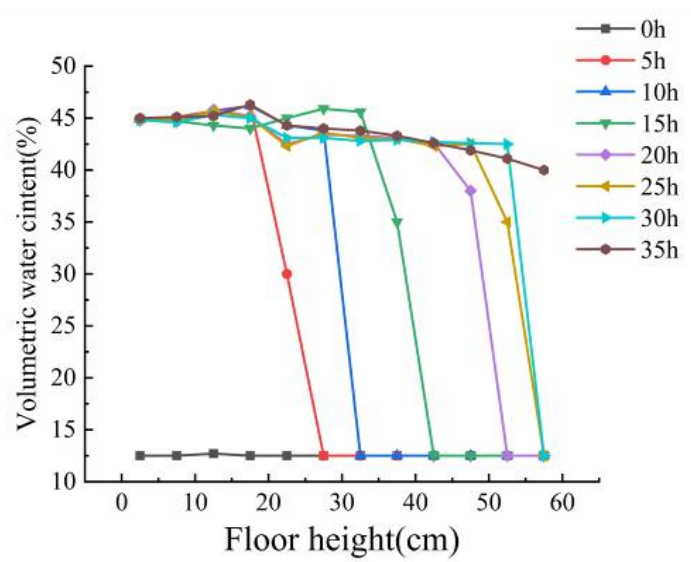

(a) 


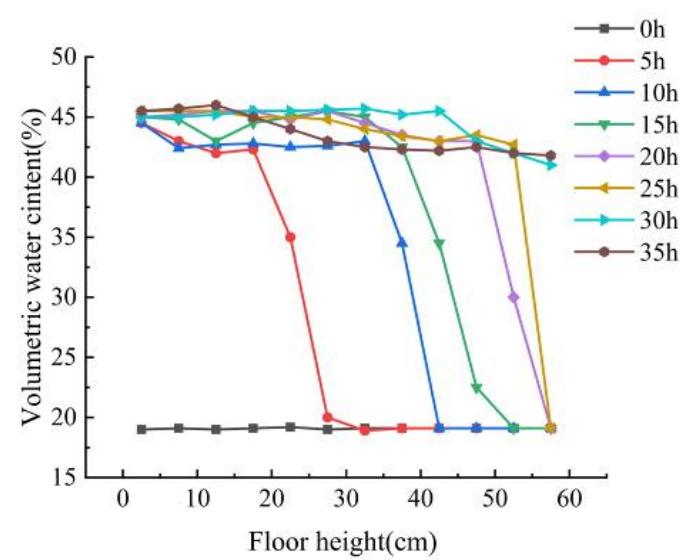

(b)

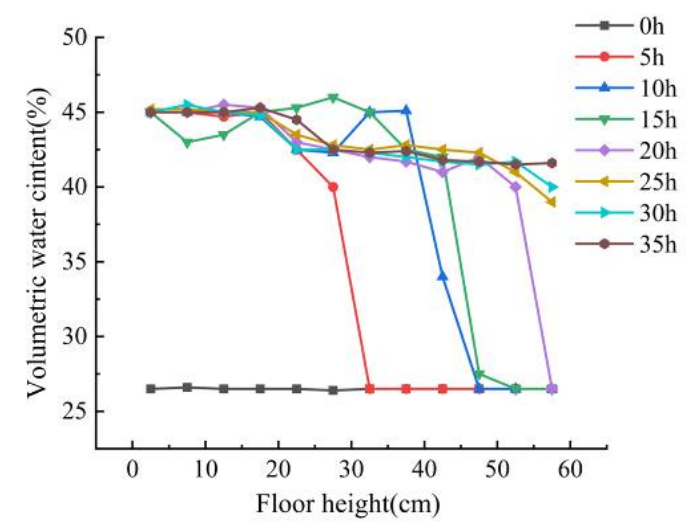

(c)

Fig.8. Relationship curves between moisture migration laws and initial water content. (a) Sample 6. (b) Sample 7. (c) Sample 8

$w$ and $\psi$ represent the initial water content and the total water potential. The soil mass is assumed to be isotropic, and $k(w)$ is the hydraulic conductivity. Moreover, moisture migration in soil mass is one-dimensional migration with a migration height of $h$. On the basis of these hypotheses, the moisture migration equation in embankment filling can be constructed as:

$$
\frac{\partial w}{\partial t}=\frac{\partial}{\partial h}\left[k(w) \frac{\partial \psi}{\partial h}\right]
$$

Soil mass in the embankment is not a mean and an isotropic. Water is three-dimensional. Hence, the threedimensional equation of moisture migration can be expressed as follows:

$$
\frac{\partial w}{\partial t}=\frac{\partial}{\partial x}\left[k_{x}(w) \frac{\partial \psi}{\partial x}\right]+\frac{\partial}{\partial y}\left[k_{y}(w) \frac{\partial \psi}{\partial y}\right]+\frac{\partial}{\partial z}\left[k_{z}(w) \frac{\partial \psi}{\partial z}\right]
$$

where $k_{x}(w), k_{y}(w)$ and $k_{z}(w)$ are hydraulic conductivity along the $x, y$ and $z$ direction, respectively.

\section{Conclusions}

A series of systematic moisture migration tests were performed using a self-made experimental apparatus to examine the influence of the laws of properties of loess subgrade on moisture migration. Influencing laws of humidification-dehumidification cycle, dry density, and initial water content on water migration in loess fill subgrade were revealed. Several major conclusions could be drawn.

(1) Moisture migration speed is negatively correlated with the number of wetting-drying cycle, degree of compaction, and initial water content. After the stabilization of moisture migration, the final volume water content decreases with the increase of migration height.

(2) When the degree of compaction is higher, the space among soil particles is smaller and the soil particles are closer. This compaction consumes more energy for moisture migration and thus decelerates moisture migration. Given the same dry density, reaching the equilibrium of moisture migration takes a shorter time, and the migration speed is higher with the increase of initial water content.

(3) Moisture migration can be divided into hydraulic pressure-controlled and capillary-controlled stages. In the hydraulic pressure-controlled stage, water head difference is the impetus of moisture migration. However, the capillary effect becomes the impetus of moisture migration once the migration channel is formed. The moisture migration transits from the hydraulic pressure-controlled stage to the capillarycontrolled stage. Moisture migration reaches the stable equilibrium in the late capillary-controlled stage.

To sum up, moisture migration tests are performed using the self-made device. The research method and mean are appropriate. A contrast analysis of moisture migration among eight groups of loess samples is implemented considering the influences of multiple factors. These factors can reflect water migration characteristics in loess fill subgrades to a certain extent and provide references for engineering construction. Moisture migration is the consequence of the coupling of water, heat, and power in practical projects. This study focuses on the effects of water and hydraulic coupling, which are different from practical projects. Future studies can analyze moisture migration laws by combining the coupling effect of multiple factors to make research conclusions closer to practical situations and expand the range of application.

\section{Acknowledgements}

The authors are grateful for the support provided by the China Railway Corporation Science and Technology Research and Development Plan (Grant No. 2017G007-G) and the National Natural Science Foundation of China (Grant No. 41672305) and the Shaanxi Provincial Key Research and Development Program (Grant No. 2017ZDXM-SF-082).

This is an Open Access article distributed under the terms of the Creative Commons Attribution License

\section{References}

1. Kay, B., Dexter, A., "The influence of dispersible clay and wetting/drying cycles on the tensile strength of a red-brown earth". Australian Journal of Soil Research, 30(3), 1992, pp.297-299.
2. Malusis, M. A., Yeom, S., Evans. J. C., "Hydraulic conductivity of model soil-bentonite backfills subjected to wet-dry cycling". Canadian Geotechnical Journal, 48(8), 2011, pp.1198-1211. 
3. Mao, Y. C., Li, G. Y., Lei, J. X., "Experimental study on the effects of wetting-drying cycles of compacted loess". Advanced Materials Research, 8(31), 2013, pp.326-330.

4. Qian, C., "Study on Mechanical Properties and Microstructural Changes of Heifangtai Loess under Freeze-Thaw Action". Doctoral Dissertation of Geosciences University, China, 2018, pp.3-13.

5. Liu, X. J., Yan, Y. C., Luo, Y., "Experimental research on the transfer' law of water and transferring quantity in unsaturated loess". Journal of Xi'an University of Architecture \& Technology (Natural Science Edition), 47(1), 2015, pp.56-61.

6. Thomas, H. R., Ress, S. W., "Modeling field infiltration into unsaturated clay". Journal of Geotechnical Engineering, 116(10), 1990, pp.1483-1500.

7. Thomas, H. R., Ress, S. W., "The numerical simulation of seasonal soil drying in an unsaturated clay soil". International Journal for Numerical and Analytical Methods in Geomechanics, 17(2), 1993, pp.119-132.

8. Wang, T. X., Hu, C. S., "Study on coupling problem of temperature field and moisture transfer field of subgrade in permafrost regions". China Civil Engineering Journal, 36(12), 2003, pp.93-97.

9. Johnson, K. A., Sitar, N., "Hydrologic conditions leading to debrisflow initiation". Canadian Geotechnical Journal, 27(6), 1990, pp.789-801.

10. Sammori, T., Tsuboyama, Y., "Parametric study on slope stability with numerical simulation in consideration of seepage process". In: Proceedings of the 6th Symposium on Landslide, Rotterdam, Holland: AA Balkema, 1991, pp.539-544.

11. Zhang, Z. Q., Wu, Q. B., Wen, Z., "Analysis of water accumulation process of asphalt pavement frozen soil subgrade". China Journal of Highway and Transport, 26(02), 2013, pp.1-6.

12. Wang, G. Y., Xiao, W., Huang, Y. M., "Indoor simulation of water diffusion and condensation migration of subgrade soil". Journal of Central South University (Science and Technology), 46(12), 2015, pp.4657-4663.

13. Bai, Q. B., Li, X., Tian, Y. H., et al., "Study on coupled equations and numerical simulation of frozen soil water and heat". Chinese Journal of Geotechnical Engineering, 37(S2), 2015, pp.131-136.

14. Gasmo, J. M., Rahardjo, H., Leong, E. C., "Infiltration effects on stability of a Residual soil slope". Computers and Electronics in Agriculture, 26(2), 2000, pp.145-165.

15. Mcroberts, E. C., Morgenstern, N. R., "The Stability of Thawing Slopes”. Canadian Geotechnical Journal, 11(4), 1974, pp.447-469.
16. Lam, L., Fredlund, D. G., Barbour, S. L., "Transient seepage model for saturated-unsaturated soil system: a geotechnical engineering approach". Canadian Geotechnical Journal, 24(4), 1988, pp.565580.

17. Cui, Y. J., Gao, Y. B., Ferber, V., "Simulating the water content and temperature changes in an experimental embankment using meteorological data". Engineering Geology, 114(3), 2010, pp.456471.

18. Cao, L., "Monitoring of hydrothermal characteristics and frost heave development process in the road section of seasonal frozen soil area in China". Journal of Glaciology and Geocryology, 39(05), 2017, pp.1065-1074.

19. Liu, Y. W., Zhang, W., Feng, S. J., "Response of water migration in high railway foundation under complex atmospheric environment". Rock and Soil Mechanics, 39(7), 2018, pp.2574-2582.

20. Xie, N., Zou, W. L., Yan, Q. R., "Experimental research on response of a loess subgrade slope to artificial rainfall". Journal of Sichuan University (Engineering Science Edition), 41(4), 2009, pp.31-36.

21. Liu, W. R., Gao, J. P., "Numerical modelling on water migration in loess subgrade”. Journal of Chang'an University (Natural Science Edition), 26(4), 2006, pp.5-7.

22. Liu, X. P., "Study on Water Action Mechanism and Migration Characteristics of Unsaturated soil subgrade". Doctoral Dissertation of Hunan University, China, 2008, pp.3-11.

23. Harlan, R. L., Nixon, J. F., "Ground thermal regime". Geotechnical Engineering for cold regions, 15(2), 1979, pp.103-108.

24. Zhao, G., Tao, X. X., Liu, B., "Experimental study on water migration in undisturbed soil during freezing and thawing process". Chinese Journal of Geotechnical Engineering, 31(12), 2009, pp.1952-1957.

25. Wang, T. H., He, Z. Q., Zhao, S. D., "Experimental study on vaporous water transference in loess and sandy soil". Chinese Journal of Rock Mechanics and Engineering, 24(18), 2005, pp.3271-3275.

26. Zhai, J. Y., Wei, G. X., "Influence of dry density on moisture migration parameter of unsaturated expansive soil". Rock and Soil Mechanics, 30(11), 2009, pp.3337-3341.

27. Chen, J. B., Kong, L. W., Zhao, Y. L., "On influence factors of suction and deformation of unsaturated soil under evaporation and transpiration effect". Rock and Soil Mechanics, 28(9), 2007, pp.1767-1778. 